\title{
A New Approach to Control of Anemia in "At Risk" Infants and Children Around the World 2004 Ryley-Jeffs Memorial Lecture
}

\author{
STANLEY ZLOTKIN, MD, PhD, FRCPC, Professor, Departments of Paediatrics and Nutritional Sciences, University of Toronto; \\ Senior Scientist, Program in Metabolism, Research Institute, Hospital for Sick Children; Research Fellow, \\ Centre for International Health, University of Toronto; Head, Division of Gastroenterology and Nutrition, \\ Hospital for Sick Children, Toronto, ON
}

\begin{abstract}
An estimated $60-80 \%$ of the world's population is affected by iron deficiency. It is the most common preventable nutritional deficiency in the world, despite global goals for its reduction. Young children are the highest risk group, particularly during their rapid period of growth. Anemia in infants and young children is known to have a negative impact on motor and socioemotional development and cognitive function. A new intervention, microencapsulated ferrous fumarate Sprinkles, has been developed to treat iron deficiency. The development process took the intervention from the idea stage to the research stage to the implementation stage. Multiple micronutrient Sprinkles are a breakthrough in meeting the global challenge to reduce childhood anemia due to iron and other micronutrient deficiencies. The goal of the Sprinkles project is to reduce the global burden of childhood anemia by promoting healthy weaning practices, by advocating home-fortification strategies to increase the micronutrient content of weaning foods, and by making Sprinkles widely available, particularly in developing countries. (Can J Diet Prac Res 2004; 65:136-138)
\end{abstract}

\section{Résumé}

On estime qu'environ 60 à $80 \%$ de la population mondiale souffre de carence en fer. Il s'agit de la carence nutritionnelle facile à prévenir la plus répandue malgré les objectifs de réduction à l'échelle mondiale. Les jeunes enfants sont les plus à risque, en particulier durant leur période de croissance rapide. On sait que l'anémie chez les nourrissons et les jeunes enfants exerce des effets négatifs sur le développement moteur et socio-émotionnel de même que sur la fonction cognitive. Une nouvelle intervention, le fumarate ferreux microencapsulé Sprinkles, a été conçue pour traiter la carence en fer. Le processus de mise au point s'est étendu du stade de la conception jusqu'à celui de la recherche et de l'implantation. Les micronutriments multiples Sprinkles sont une découverte qui aidera à relever le défi mondial de réduction de l'anémie infantile attribuable à la carence en fer ou en d'autres micronutriments. Le but du projet Sprinkles est de réduire le fardeau mondial de l'anémie infantile en faisant la promotion de saines pratiques de sevrage, en préconisant des stratégies d'enrichissement à domicile afin d'augmenter la teneur en micronutriments des aliments de sevrage et en rendant Sprinkles largement accessible, en particulier dans les pays en développement.

(Rev can prat rech diétét 2004; 65:136-138)

\section{INTRODUCTION}

The latest World Health Organization (WHO)/United Nations Children's Fund (UNICEF) estimates suggest that the number of children with iron deficiency and anemia is approximately 750 million. Iron deficiency remains the most common preventable nutritional deficiency in the world, despite global goals to reduce it over the past decades (1). In developing countries, particularly in Africa and South Asia, the prevalence of iron deficiency anemia (IDA) is often as high as $80 \%$ in young children (2). Repeated documentation indicates that children with iron deficiency and anemia are compromised in terms of motor, cognitive, and socioemotional development (3). Well-controlled longitudinal studies reveal that these children have reduced learning capacity and school achievement, and as adults they have decreased wages and work capacity. Although the exact etiology of the impairment has not been identified, an association between IDA and

impaired cognitive performance has been clearly documented. Moreover, Dr. Susan Horton, a health economist at the University of Toronto, has just published estimates of the worldwide economic impact of childhood iron deficiency. Dr. Horton suggests that its burden results in a $4.5 \%$ reduction of the gross domestic product (through reduced learning and ultimately poorer paying jobs) (4).

Of the three most common reversible nutritional deficiencies affecting children, two (iodine and vitamin A deficiencies) are being addressed rationally and successfully through national legislation requiring central iodization of salt and high-dose vitamin A capsules delivered nationwide through the Extended Program on Immunization. This is not the case for iron deficiency, for which national policies or appropriate delivery systems often do not exist. Current recommendations for general food fortification likely will benefit only older 
children and adults who consume sufficient quantities of these foods. This strategy will not be successful for infants and young children, who consume smaller quantities of food and therefore require higher fortification levels to meet their iron needs. Fortifying general foods at higher levels would be inappropriate because of the potential toxicity to adults, especially men, who eat the most food. Thus, the challenge is to find safe, sustainable, and effective ways to meet children's iron needs, particularly in developing countries.

\section{Developing an innovative approach}

Recognizing that current solutions to the problem of iron deficiency anemia were unsuccessful, UNICEF challenged the international nutrition community to develop a new approach to anemia prevention. Our research group took up this challenge, drawing on past successes to develop a simple and inexpensive strategy that focused on infants and children in developing countries. Our innovation was based on the principle that commercial targeted fortification has been largely successful in controlling iron deficiency anemia in the West. We also were inspired by a legacy at the Hospital for Sick Children, where Pablum was invented in 1929 to improve infant nutrition; Sprinkles evolved as a novel method to deliver iron and other micronutrients to children at risk, through use of a "home-fortification" approach (5).

\section{What are Sprinkles?}

Sprinkles are single-dose sachets (like small packets of sugar or artificial sweetener) containing micronutrients in powder form (encapsulated ferrous fumarate; zinc; vitamins A, C, and D; and folic acid). The sachet contents are easily sprinkled onto complementary (weaning) foods prepared in the household. Any homemade or unfortified food can be fortified by the addition of Sprinkles, and hence the term "home fortification." Our research group developed Sprinkles to overcome many of the side effects and disadvantages of iron drops, as well as to provide low-cost delivery of a daily amount of other vitamins and minerals to prevent and treat common micronutrient deficiencies among children. Lipid encapsulation of the iron prevents its interaction with food and masks its taste, and thus taste and colour changes are minimal in the food to which Sprinkles are added. Another advantage of Sprinkles is that they are a food-based rather than medical intervention. Furthermore, the use of Sprinkles does not necessitate a change in the usual complementary foods prepared in the household. Sprinkles can be added to any complementary food: yogourt, pureed fruits, etc.

\section{Evaluation of Sprinkles}

The development of Sprinkles followed a pathway that included three discrete components: 1 . demonstrating efficacy and effectiveness; 2. obtaining a sustainable, inexpensive supply; and 3. scaling up to countrywide distribution programs.

Over the past five years, we have completed six randomized, controlled trials (RCTs) in four countries. These trials involved more than 2,000 anemic and non-anemic infants and children. Our goal for these studies was to evaluate the efficacy and acceptability of Sprinkles in controlled settings, and to describe the absorption of iron from Sprinkles. In collaboration with the Ghanaian Ministry of Health, Kintampo Health Research Centre, our first RCT demonstrated that in anemic infants, Sprinkles achieved a rate of cure similar to that of the reference standard, iron drops (6-8). Approximately $60 \%$ of infants went from an anemic to a non-anemic state in two months, which is a successful outcome in a malaria-endemic area. In a second study (during the dry season), we were able to confirm our initial observations that iron Sprinkles (with and without zinc) are efficacious in treating anemia in infants.

The cure rate in 304 anemic infants was $69 \%$ with Sprinkles. Moreover, in Bolivia, a non-malaria-endemic area, we achieved a $90 \%$ cure rate for anemic infants (unpublished data). Overall, cure rates in our RCTs have ranged from $55-90 \%$.

Results from studies of preschool children in China and young Aboriginal children in Canada have demonstrated similar efficacy of Sprinkles compared with drops in anemia prevention (9). However, higher compliance rates were achieved with Sprinkles, and parents and caregivers preferred them.

Three components of Sprinkles differentiate them from drops. Sprinkles are microencapsulated; they are added to a food, and they contain other micronutrients in addition to iron. These components, either individually or collectively, may influence the bioavailability of the iron and, thus, the optimum dose to be included within a sachet. Although we had completed in vitro studies to demonstrate that the lipid encapsulate dissolves in a low-pH "gastric" environment, we could not easily extrapolate these results in vivo. Because Sprinkles are primarily added to cereal-based foods that are usually high in phytates and fibre, which can bind iron, we were uncertain about iron bioavailability when Sprinkles were added to these foods. Finally, interactions between nutrients may have an impact on bioavailability (e.g., zinc may affect iron absorption), and thus we could not assume that the iron from Sprinkles would be well absorbed. Using intrinsically labelled dual isotopes of iron, we demonstrated that anemic infants absorb iron from Sprinkles about twice as efficiently as do non-anemic infants (8.25\%, range: $2.9-17.8 \%$ versus $4.65 \%$, range: $1.5-12.3 \%$ ) (10). Comparing these absorption values with the new Dietary Reference Intake standards for infants, we concluded that during infancy, Sprinkles iron absorbed from a maize-based porridge met and surpassed iron needs for absorbed iron. Using these results, we estimated that a 12.5-mg iron dose from Sprinkles should be adequate for use in large-scale distribution for the prevention and treatment of mild to moderate anemia. The next obvious questions related to ease of use, acceptability, and effectiveness.

\section{Acceptability of Sprinkles}

In each of the studies to date, we have questioned caregivers about infants' response to Sprinkles compared with their 
response to drops, the impact of Sprinkles on the food to which they are added (change in taste, colour, or consistency), the acceptability of the sachet as a delivery vehicle, and perceived side effects. Invariably, the response to Sprinkles has been positive. No appreciable change occurs in the foods to which Sprinkles are added, and thus infants do not object to their use; infants' teeth are not stained; the sachet is easy to use, and the only significant side effect is an expected darkening of infants' stools.

\section{Sustainable supply}

When we were preparing for the first RCT, we quickly realized that the only way to obtain a supply of Sprinkles was by making them ourselves. Because this was a new product, no commercial supply existed. Thus, the first batches of Sprinkles were mixed in the hospital kitchen and packaged by a local commercial co-packer. Within three years, as the first studies were demonstrating the efficacy of Sprinkles, the need for a reliable high-quality supply was apparent. In 2000, the H.J. Heinz Company of Pittsburgh expressed an interest in the Sprinkles program as a public-private partnership. The fit with the company was close to perfect. One of their product lines is jarred and packaged baby foods, and the H.J. Heinz Company is among the largest fillers of sachets - albeit sachets of ketchup, mustard, and vinegar - in the world. The company thus has great expertise in this area. Currently, the H.J. Heinz Company provides support for overseas research initiatives, expertise in evaluating consumer needs, and a supply of Sprinkles for research. Sprinkles are supplied on a cost-recovery basis for non-commercial distribution, and Heinz enjoys the benefits of being publicly associated with a significant humanitarian initiative.

\section{Countrywide distribution programs}

Progressing from research to countrywide distribution is extremely challenging. This process involves identifying sustainable distribution methods to reach and provide Sprinkles to the most vulnerable populations in the developing world. From our experience in Mongolia, we have determined that distributing Sprinkles in partnership with a non-governmental organization (NGO) (World Vision) is feasible. In Mongolia, the two major nutrition-related problems in children are anemia (affecting $42 \%$ of children under age two) and vitamin D deficiency rickets (affecting 48\% of children). The Sprinkles sachets distributed in Mongolia include both iron and vitamin D. We have successfully distributed Sprinkles (containing iron, zinc, vitamins A, C, and D, and folic acid) to more than 15,000 children in seven districts. To date, coverage has been over $80 \%$, at a cost of about $\$ 0.03$ per sachet. Within program areas, the prevalence of anemia $(\mathrm{Hb}<115 \mathrm{~g} / \mathrm{L})$ in children under age five decreased from $42 \%(\mathrm{~N}=1,478)$ and $47.5 \%(\mathrm{~N}=1,289)$ at baseline to $24 \%(\mathrm{~N}=937)$ and $25.8 \%(\mathrm{~N}=889)$ at final survey $(p=0.01)$. This significant decline in the rate of anemia is unsurpassed in global public health interventions for anemia control.

Despite these positive results, without committed, longterm financial input from the parent NGO, sustainability is not guaranteed. Clearly, sustainability over the long term is most likely if a program can become self-financing. This may be achieved through commercial market integration, through public and private partnerships that use effective social marketing campaigns, or possibly through programs that include microcredit.

\section{CONCLUSION}

The Sprinkles Group at the Hospital for Sick Children is committed to developing Sprinkles to treat and prevent nutritional anemias and micronutrient deficiencies in vulnerable populations through research, program development, advocacy, and technology transfer. In developing Sprinkles as a sustainable home-fortification strategy, we seek to improve the health and well-being of infants, children, and pregnant women, so that they can meet their genetic potential for growth, health, and development.

We believe that achieving our goal of sustainable distribution will be possible only through partnerships with government and United Nations agencies, NGOs, and the private sector. Our ongoing relationship with the Ghanaian Ministry of Health, our multilateral funding sources, our links to the many NGOs implementing nutrition programs, and our partnership with the H.J. Heinz Company are, we believe, good examples of successful partnership development for the potential eradication of a major global nutrition problem.

\section{References}

1. Yip R. Prevention and control of iron deficiency: policy and strategic issues. J Nutr 2002;132:802S-5S.

2. Stoltzfus RJ. Iron deficiency anemia: reexamining the nature and magnitude of the public health problem: summary implications for research and programs. J Nutr 2001:131;697S-700S.

3. Grantham-McGregor S, Ani C. A review of studies on the effect of iron deficiency on cognitive development in children. J Nutr 2001;131:649S-68S.

4. Horton S, Ross J. The economics of iron deficiency. Food Policy 2003:28:51-75.

5. Schauer C, Zlotkin SH. "Home-fortification" with micronutrient Sprinkles-a new approach for the prevention and treatment of nutritional anemias. Paediatrics Child Health 2003;8:87-90.

6. Zlotkin SH, Arthur P, Antwi KY, Yeung G. Treatment of anemia with microencapsulated ferrous fumarate plus ascorbic acid supplied as "sprinkles" to complementary (weaning) foods. Am J Clin Nutr 2001;74:791-5.

7. Zlotkin SH, Antwi KY, Schauer C, Yeung G. Use of microencapsulated ferrous fumarate sprinkles to prevent recurrence of anemia in infants and young children at high risk. Bull World Health Organ 2003;81:108-15.

8. Zlotkin S, Arthur P, Antwi KY, Schauer C, Yeung G, Piekarz A. Randomized controlled trial of multi versus single-micronutrient supplementation for treatment of anemic infants. J Nutr 2003;133:1075-80.

9. Christofides A, Zlotkin S, Schauer C. Impact of Micronutrient Sprinkles for the Treatment and Prevention of Iron Deficiency in Canadian First Nations and Inuit Infants 4-18 months old. FASEB J 2003;17:A1085.

10. Tondeur M, Schauer S, Christofides A, et al. Determination of iron absorption from intrinsically labeled microencapsulated ferrous fumarate (Sprinkles) in infants with varying iron/hematologic status using a dual stable isotope method. Am J Clin Nutr. In press 2004. 